Universidade de Brasília

Centro de Excelência em Turismo

Curso de Especialização em Hospitalidade

\title{
SAZONALIDADE DE DEMANDA TURÍSTICA: HOTÉIS DE PEQUENO PORTE DE CALDAS NOVAS (GOIÁS)
}

\author{
AUGUSTO LIRA DA ROCHA
}

Orientador: Eli Siqueira

Monografia apresentada ao Centro de Excelência em Turismo da Universidade de Brasília como requisito parcial para a obtenção do certificado de Especialista em Hospitalidade. 
Universidade de Brasília

Centro de Excelência em Turismo

Curso de Especialização em Hospitalidade

\section{SAZONALIDADE DE DEMANDA TURÍSTICA: HOTÉIS DE PEQUENO PORTE DE CALDAS NOVAS (GOIÁS)}

\section{AUGUSTO LIRA DA ROCHA}

Banca Examinadora

Eli Siqueira, Mestre

Orientador

\section{Leonor Moreira Câmara, Doutora}

Examinadora 


\title{
AUGUSTO LIRA DA ROCHA
}

Sazonalidade de demanda turística: hotéis de pequeno porte de Caldas Novas (Goiás)

Banca Examinadora

\author{
Eli Siqueira, Mestre \\ Orientador
}

Leonor Moreira Câmara, Doutora

Orientadora 
DEDICATÓRIA

Dedico a Deus por ter me dado forças, sabedoria, inteligência, paciência e capacidade para concluir este trabalho; à minha filha Kellyse e à minha mãe, pela força e dignidade. 
AGRADECIMENTOS

Aos professores e amigos, Abel Ambrósio pelo incentivo, Elisângela pela oportunidade e Mariana pelas dicas. Aos amigos, Ronaldo, Cristiane e Daylane pelo carinho. Em Especial, meu agradecimento ao meu orientador e mestre Eli Siqueira. 
"Quem é firme nos seus propósitos, molda o mundo a seu gosto".

\section{Goethe}




\section{RESUMO}

O presente trabalho aborda a sazonalidade que afeta o município turístico de Caldas Novas (GO), exclusivamente os hotéis de pequeno porte (categoria econômica), que são administrados pelos próprios familiares. A linha de pesquisa foi analisar a realidade dos hotéis de pequeno porte por meio da pesquisa elaborada e aplicada pela Agência Goiana de Turismo. Assim, comenta-se a necessidade de se conhecer o perfil do turista de lazer, a oferta de produtos e serviços e propor alternativas de aumento do fluxo de turista, buscando diminuir a sazonalidade. Finalmente, recomenda-se um programa de desenvolvimento sustentável com a participação da comunidade no planejamento da atividade turística, gerando mais empregos e criando oportunidade para aumentar a rentabilidade dos meios de hospedagem.

Palavras - chaves: Sazonalidade; Meios de Hospedagem; Caldas Novas (GO). 


\begin{abstract}
This present paper reports on the seasonality that afects the touristic city council of Caldas Novas (GO), specially the small hotels (Economic Category) that are managed by the own family. The research was based on analizing the reality of small hotels by a research elaborated and applied by the Tourism Agency of Goiana. Thus, it is important to knowlege the profile of the leisure tourist, the product and service offering and propose alternatives to increase the rise of tourists aiming the seasonality decrease. Finally, a sustainable development program is recommended with the participation of the community on the touristic activity planning, offering more jobs and bringing oportunities to increase the profitability of the lodging.
\end{abstract}

Key-Words: Seasonality; Lodging; Caldas Novas (GO). 
LISTA DE TABELAS X X

LISTA DE QUADROS XI

LISTA DE ABREVIATURAS XII

1. INTRODUÇÃO 13

2. HOTELARIA NO BRASIL 15

3. REGIÕES TURÍSTICAS DO ESTADO DE GOIÁS 19

3.1 Caminho das Águas - Caldas Novas - Goiás 19

3.2 Balneoterapia 20

3.3 Ecologia 20

3.4 Culinária 21

3.5 Atrativos Turísticos de Caldas Novas (GO) 21

4. A CIDADE DE CALDAS NOVAS (GOIÁS) 24

4.1 População e Densidade 25

4.2 Serviços Básicos e Essenciais 26

4.3 Economia da Cidade $\quad 28$

$\begin{array}{ll}4.4 \text { Turismo } & 30\end{array}$

5. ACESSOS 33

5.1 Transporte Rodoviário 34

6. ABORDAGEM METODOLÓGICA 36

6.1 Delimitação do Universo da Pesquisa 36

6.2 Universo da Pesquisa 36

6.3 Sazonalidade 36

7. PÉRFIL DO TURISTA 38

8. CONCLUSÃO 48

9. REFERÊNCIAS BIBLIOGRÁFICAS 50 


\section{LISTA DE TABELAS}

Tabela 1 - Evolução da População 


\section{LISTA DE QUADROS}

Quadro I - Distâncias das Principais Cidades 25

Quadro II - Rede Hospitalar 27

Quadro III - Segundo a OMT 28

Quadro IV - Rede Escolar $\quad 30$

Quadro V - Meios de Hospedagem com mais de 5 e até $20 \mathrm{UHs} 32$

Quadro VI - Acessos Rodoviários e Cidades 33

Quadro VII - Empresas de Transporte Rodoviário 34

Quadro VIII - Origem 38

Quadro IX - Sexo 38

Quadro X - Idade 38

Quadro XI - Estado Civil 39

Quadro XII - Local de Hospedagem 39

Quadro XIII - Gasto Médio $\quad 40$

Quadro XIV - Renda Pessoal $\quad 41$

Quadro XV - Agrupamento $\quad 42$

Quadro XVI - Motivo de Viagem 43

Quadro XVII - Visita à Região $\quad 43$

Quadro XVIII - Época de Visitação $\quad 44$

Quadro XIX - Tempo de Permanência 44

Quadro XX - Meio de Comunicação $\quad 45$

Quadro XXI - Meio de Transporte 46

Quadro XXII Acesso aos Guias $\quad 46$ 


\section{LISTA DE ABREVIATURAS}

AGETUR

-Agência Goiana de Turismo

ANATEL -Agência Nacional de Telecomunicação

CELG Centrais Elétricas de Goiás CET/UnB Centro de Excelência da Universidade de Brasília CTC Caldas Thermas Clube DEMAE -Departamento Municipal de Água e Esgoto EMBRATUR -Instituto Brasileiro de Turismo FUNGETUR Fundo Geral do Turismo IBGE Instituto Brasileiro de Geografia e Estatística

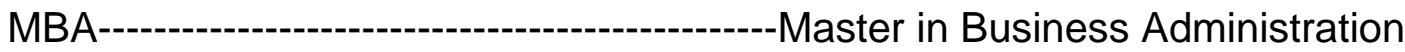
OMT Organização Mundial do Turismo PESCAN Parque Estadual Serra de Caldas Novas

PIB Produto Interno Bruto

SEBRAEServiço de Apoio às Micro e Pequenas Empresas SENAC Serviço Nacional de Aprendizagem Comercial SETUR-----------------Secretaria de Turismo e Cultura de Caldas Novas (GO) SUDAM--------------------Superintendência do Desenvolvimento da Amazônia SUDENESuperintendência do Desenvolvimento do Nordeste UEG Universidade Estadual de Goiás $\mathrm{UH}$ Unidade Habitacional UNICALDAS Faculdade de Caldas Novas 


\section{INTRODUÇÃO}

As mudanças que afetam (ou afligem) o mercado turístico não são segredo. A globalização, a desregulamentação de mercados, as privatizações e os avanços tecnológicos criam um ambiente repleto de incertezas. A manutenção e o sucesso dos negócios, cada vez mais, depende de pesquisa e de planejamento.

O crescente aumento da concorrência no ramo da hospitalidade, decorrente dos grandes investimentos das redes que atuam no setor e o surgimento de inúmeros flats, por todo o País, intensificam a necessidade de compreender o consumidor, suas necessidades e suas motivações. Essas características são reflexos da sociedade pós-industrial, em que, a partir da enorme oferta de informação, o consumidor se tornou mais exigente e consciente. Expressões sobre qualidade e marketing tornaram-se comuns, indicando crescente preocupação com a oferta de produtos e de serviços.

Com o contínuo crescimento do fenômeno turístico, a tendência mais marcante é a descentralização de certos núcleos receptivos, responsáveis por uma elevada procura por parte da demanda. Nessa disputa internacional pelo mercado turístico, a China é o país de maior potencial. A Organização Mundial de Turismo (OMT) aponta o mercado chinês como o de melhor perspectiva para as primeiras décadas do século XXI. Em oitavo lugar no ranking internacional, a OMT projeta, para a China, crescimento médio de $8 \%$ ao ano entre os anos de $1995 \mathrm{e}$ 2020. Confirmadas essas projeções, o país chegará, ao final da segunda década do próximo século, em primeiro lugar no ranking de turistas.

Considera-se empresa hoteleira a pessoa jurídica que explore ou administre meio de hospedagem e que tenha em seus objetivos sociais o exercício de atividade hoteleira.

O presente trabalho tem como objetivo analisar vinte e seis meios de hospedagem (de auto classificação) do complexo hoteleiro de Caldas Novas (GO) até 31 de outubro de 2003, que tenham mais de 5 e até 20 Unidade Habitacionais 
(UHs) e tenham incluso café-da-manhã na diária, ou seja, hotéis de pequeno porte (categoria econômica), administrados pelo próprio proprietário e que ofereçam: Apartamentos - quarto de dormir com um banheiro privativo e local apropriado para guardar roupas e objetos pessoais e com ou sem piscina e estacionamento. Equipamentos - TV, frigobar ou geladeira, circulador de ar e/ou ar condicionado.

Por compreender que para essa investigação se faz necessário analisar a cidade de Caldas Novas como pólo turístico e maior estância hidrotermal do mundo, enfatizar-se-á a análise da sazonalidade, dos meios de hospedagem de categoria econômica e do turismo, como propulsor de sua economia.

Os meios de hospedagem analisados, dedica-se a caracterizar a empresa como uma opção mais viável economicamente para o turista, analisar o mercado consumidor de turismo de lazer (Turistas: famílias e excursões) e demonstrar sua rentabilidade (taxa de ocupação) e sazonalidade.

Diante do mencionado, não se pretende fazer longas reflexões teóricas, mas sim observações pertinentes ao contexto em que se vive, especialmente no que se refere às perspectivas do turismo em Caldas Novas (GO), de acordo com a pesquisa elaborada e aplicada pela Agência Goiana de Turismo (AGETUR) nos meses de maio (baixa temporada - com amostra de 426 questionários) e julho (alta temporada com amostra de 561 questionários), em 2002, na cidade de Caldas Novas (GO). 


\section{HOTELARIA NO BRASIL}

No Brasil, há indícios de que o desenvolvimento da hotelaria foi impulsionado pela transferência da corte portuguesa para o Brasil. IGNARRA (1999, pág. 19) evidência a situação da hotelaria brasileira anterior a este período, ao relatar que: "(...) até a segunda metade do século XVIII não havia hospedarias na cidade do Rio de Janeiro." O autor também relata que em São Paulo só se tem notícias de hotéis, com algum padrão de qualidade, em torno do ano de 1870 e que apenas em 1908, com a inauguração do Hotel Avenida no Rio de Janeiro, iniciou-se a hotelaria moderna no país.

A hotelaria brasileira tem atravessado significativas mudanças ao longo do seu desenvolvimento. ANDRADE, BRITO e JORGE (2000, pág. 25) apontam alguns marcos para a hotelaria no Brasil:

\section{8}

Mudança da corte portuguesa para o Brasil, o que incentivou a implantação de hospedarias no Rio de Janeiro-(RJ).

\section{1}

Vários hotéis já possuíam telefone.

1904

Primeira lei de incentivos para a implantação de hotéis no Rio de Janeiro-(RJ).

1923

\section{Hotel Esplanada ao lado do Teatro Municipal:}

* 250 apartamentos;

* magnífico hall de entrada em mármore carrara;

* 3 luxuosos salões e restaurante;

* salão de chá, ponto de encontro da elite paulistana. 


\section{São Paulo-(SP)}

O desenvolvimento da hotelaria esteve atrelado ao turismo de negócios.

\section{Rio de Janeiro-(RJ)}

O desenvolvimento deu-se pelo fato da cidade ser a capital do país e de ganhar notoriedade em âmbito internacional devido às inúmeras belezas naturais e à música popular brasileira de Ari Barroso e Carmen Miranda.

\section{Marco Hoteleiro}

Copacabana Palace, famoso ainda hoje, cuja construção contribuiu de forma decisiva para transformar o Rio de Janeiro em pólo de turismo de lazer.

\section{Década de 1940}

Grande desenvolvimento da hotelaria graças ao incentivo dos governos estaduais.

\section{Hotéis Cassinos:}

* Parque Balneário - Santos-(SP);

* Grande Hotel de Poços de Caldas-(MG);

* Grande Hotel Araxá-(MG);

* Grande Hotel São Pedro - Águas de São Pedro-(SP).

O Grande Hotel São Pedro foi restaurado e ocupa lugar importante no mercado de turismo de lazer e convenções. Esse hotel abriga a maior escola de hotelaria da América Latina e é administrado pelo Serviço Nacional de Aprendizagem Comercial (SENAC) de São Paulo-(SP).

\section{6}

Proibição dos jogos de azar e fechamento dos cassinos, inviabilizando os hotéis construídos para esse fim.

Década de 1960: Brasília (DF)

Nacional, Brasília Palace, Brasília Imperial, Itamaraty, Alvorada. 
Com a proibição do jogo, a hotelaria, em geral, deixou de crescer, somente retomando o desenvolvimento com os incentivos fiscais da Operação 63, do Banco Central. Essa medida favoreceu ao grande crescimento da Rede Othon uma das maiores do mundo - e de outras redes como Vila Rica e Luxor, todas com capital fechado e administrado por família.

\section{6}

Criação do Instituto Brasileiro de Turismo (EMBRATUR) e do Fundo Geral do Turismo (FUNGETUR), que viabilizaram a implantação de grandes hotéis, até mesmo nas áreas da Superintendência do Desenvolvimento da Amazônia (SUDAM) e da Superintendência do Desenvolvimento do Nordeste (SUDENE).

\section{8}

Inauguração do primeiro clube-hotel com piscinas termais de Caldas Novas (GO), o Caldas Thermas Clube (CTC).

\section{2}

Inauguração da rede Hilton - o São Paulo Hilton - que marca a virada na administração hoteleira profissional no Brasil.

\section{0}

Entrada definitiva das cadeias hoteleiras internacionais no país.

As perspectivas para o desenvolvimento da hotelaria apresentam - se bastante promissoras. Entende-se que a atividade turística promove o intercâmbio comercial e cultural entre as nações, dentre outros aspectos, sendo responsável pelo incremento das divisas de um País. Baseadas nesse princípio, grandes cadeias internacionais são atraídas para os destinos turísticos que desejam se consolidar internacionalmente, entretanto, segundo CASTELLI (1997, pág. 123 e 124) 


\begin{abstract}
o termo participação dos investimentos estrangeiros é impropriamente aplicado, (....) temos a firme convicção de que muitos países do terceiro mundo, se for feita uma análise minuciosa, são os que estão financiando o turismo dos países desenvolvidos. Quantas empresas hoteleiras multinacionais se instalaram nos países do terceiro mundo com todas as regalias? Isto é, com o mínimo de investimento próprio, correndo risco financeiro mínimo(...).
\end{abstract}

Portanto, remete a uma reflexão acerca dos resultados gerados por esses mega empreendimentos internacionais que se instalam, cada vez mais, em municípios geralmente litorâneos, passando a usufruir de incentivos fiscais e financiamentos oficiais (nem sempre disponibilizados para setores fundamentais da economia), além de receberem doações de terras privilegiadas, urbanização e saneamento. Com isso, inviabilizam, para os menores, a possibilidade do surgimento do empreendedorismo local, pois esses não têm a chance de competir nas mesmas condições. 


\section{REGIÕES TURÍSTICAS DO ESTADO DE GOIÁS}

A AGETUR, por meio de seu plano Plurianual (2004-2007), vem criando vários programas. Dentre programas e projetos do Governo de Goiás na área do Turismo, pode-se destacar o "Viaje por Goiás", que divide o estado em quatro regiões, denominadas caminhos, de acordo com suas características e tipos de atrativos turísticos:

Caminho da Biosfera, que compreende a região nordeste do Estado, com o Parque Nacional da Chapada dos Veadeiros, o Parque Nacional da Terra Ronca e cidades como Alto Paraíso, Formosa, São Domingos e Cavalcanti;

> Caminho do Sol, que engloba a região do Rio Araguaia, do Parque Nacional das Emas e o Sítio Arqueológico de Serranópolis;

Caminho do Ouro, que engloba a região marcada pela história da exploração do ouro, representada por cidades como: Pirenópolis, Cidade de Goiás, Corumbá e Jaraguá;

Caminho das Águas, representado por cidade com fontes termais como: Caldas Novas, Rio Quente, Lagoa Santa e pelos lagos como Três Ranchos, São Simão, dentre outros.

\subsection{Caminho das Águas - Caldas Novas (Goiás)}

O Estado de Goiás é responsável por apenas 3\% do fluxo nacional de turistas, valor difícil de ser aceito. Assim, a AGETUR, o Serviço de Apoio às Micro e Pequenas Empresas (SEBRAE) e o trade turístico elaboram um Plano Estratégico de Turismo das Águas Quentes (Caldas Novas / Rio Quente). Com ações de curto e médio prazos, a intenção é elevar em 15\% (240 mil a mais) a 
taxa de ocupação dos hotéis, principalmente nos períodos de baixa temporada, com incentivo ao turismo de negócios. ANSARAH (2000, pág. 36) relata que:

\begin{abstract}
Turismo de negócios corresponde a: "viagens motivadas por interesses voltados a uma atividade lucrativa ou de desenvolvimento profissional. É a ação cujo propósito é a possibilidade de realização de contatos, negócios ou obtenção de conhecimentos a eles relacionados".
\end{abstract}

De acordo com entrevista concedida ao jornal O Popular, em 31 de março de 2003, Walter Luiz Secretário de Turismo e Cultura de Caldas Novas e proprietário de hotel na cidade, acredita que o Centro de Convenções vai agregar o turismo de eventos, garantindo a ocupação na baixa temporada.

Caldas Novas é um importante destino turístico por possuir atrativos naturais, culturais, históricos e por ser o maior manancial de águas termais do mundo, com temperaturas que variam de $35^{\circ}$ a $45^{\circ}$ Celsius.

\title{
3.2 Balneoterapia
}

A balneoterapia (tratamento por meio de banhos) em águas quentes só existe graças à notável "abundância" de azoto, ácido carbônico, potássio, sódio, cálcio e magnésio no estado. Mesmo com tantos minerais, a água permanece inodora e insípida. É indicada no tratamento auxiliar de reumatismo, artrites, dispepsias, gastrites, úlcera gastro-intestinal, moléstias alérgicas, eczema, asma, bronquite crônica, diabetes, hipertensão arterial, cálculos renais e hepáticos e icterícia.

\subsection{Ecologia}

O complexo turístico de Caldas Novas recebe decoração natural, centrada no respeito à ecologia. A preservação da vegetação local propicia a presença do verde e a abundância de pássaros, como tucano, jandais, periquitos, maritacas, rolinhas, juritis, canários e beija-flores. O cenário ecológico é ideal ao relaxamento e à pratica de esportes. 


\subsection{Culinária}

A região é rica na culinária goiana, caracterizada pelo empadão goiano, frango com pequi, guariroba, derivados do milho, como pamonha e cural. Caldas Novas também oferece a comida mineira, o tradicional churrasco gaúcho e a cozinha internacional.

\subsection{Atrativos Turísticos de Caldas Novas (GO)}

a) Paróquia de Nossa Senhora das Dores

A Igreja fica na Praça Central. É especial por ser a primeira construção de Caldas Novas, datada de 1850. Vale a pena conhecer o lugar e admirar os quadros que retratam cenas da história da cidade. As missas são celebradas de segunda a sexta-feira, às 19h. Aos sábados, às 8h e às 19h30. E aos domingos, às $9 h$, às $18 h$ e às $19 h 30$.

b) Casarão

O Casarão localiza-se na rua Coronel Gonzaga s/nº É um belo prédio da Arquitetura Colonial construído em 1808. Foi restaurado por artesãos da cidade, que comercializaram objetos e produtos no interior do Casarão através do Centro de Apoio às Artes, como: artigos de cerâmica, rendas, tapeçarias, botinas, pinturas a óleo, esculturas, licores e bordados.

c) Balneário Municipal

O Balneário Municipal, criado em 1920, funciona com banhos de imersão em banheiras individuais e com o tradicional chá de douradinho após o banho, indicado para tratamento médico. A infra-estrutura do lugar é bem simples, mas a vegetação que cerca o balneário proporciona um ambiente bem agradável para quem deseja relaxar.

Está localizado na rua do Balneário $s / n^{\circ}$, logo abaixo da Prefeitura Municipal e é aberto diariamente das $7 \mathrm{~h}$ às $20 \mathrm{~h}$. 
d) Jardim Japonês

O Jardim Japonês foi construído pelo Sr. Toshiyuki Murai, que se inspirou nos jardins do século XIV, quando os monges da seita Zen-Budista saíram da China para o Japão.

Está localizado na estrada, sentido saída para Goiânia pela Av. Santo Amaro, à direita. É aberto diariamente das $8 \mathrm{~h}$ às $11 \mathrm{~h}$ e das $13 \mathrm{~h}$ às $17 \mathrm{~h}$.

e) Lago Corumbá

O Lago Corumbá possui uma área de $65 \mathrm{~km}^{2}$ e está a $5 \mathrm{~km}$ do centro de Caldas Novas (GO).

Com infra-estrutura ainda rústica, nas proximidades, existem restaurantes, marinas e lanchonetes.

Lanchas, barcos, esquis e jet skis estão disponíveis para aluguel. Com visitas a quatro cachoeiras e/ou passeio de barco com capacidade para 100 pessoas (Eco-nave). Para o passeio de barco, grupos são formados na cidade. Recomenda-se o uso de roupa leve, roupas de banho, chapéu ou boné e filtro solar.

f) Parque Estadual Serra de Caldas Novas (PESCAN)

Criado em 1970 para proteger o principal ponto de recarga do lençol termal, o PESCAN está liberado desde 1999 à visitação pública. O parque localiza-se a $5 \mathrm{~km}$ do centro da cidade, conta com guias para passeios ecológico nas trilhas da Cascatinha (700m) e Paredão (1.500m), com duração de $2 \mathrm{~h}$ a 3h. É aberto diariamente (exceto às segundas) das 8h às 16h30.

g) Feira do Luar

Localiza-se abaixo do Sambódromo, funciona somente aos sábados, a partir das 19h, com diversas barracas, nas quais os turistas podem adquirir artesanato (cerâmica, cestaria, madeira, sisal), roupas de cama, mesa e banho, 
souvenirs, tortas, doces, pães especiais, culinária regional, sucos naturais, cachaças e licores. 


\section{A CIDADE DE CALDAS NOVAS (GOIÁS)}

De acordo com Plano Diretor (2001-2004) da Prefeitura da Cidade de Caldas Novas (GO), a mesma possui uma área de $1.588 \mathrm{~km}^{2}$, localiza-se na microrregião de Meia Ponte e do sul goiano, na região Centro-Oeste do território brasileiro.

A sede municipal situa-se a $686 \mathrm{~m}$ de altitude, na posição geográfica localizada no paralelo $17^{\circ} 44^{\prime} 37^{\prime \prime}$ Sul, em interseção com o meridiano $48^{\circ} 37^{\prime} 33^{\prime \prime}$ Oeste.

Situada a 170 km de distância de Goiânia, capital do Estado de Goiás, Caldas Novas faz limite com os seguintes municípios:

- Ao norte: Santa Cruz de Goiás (69 km), Pires do Rio (80 km) e Piracanjuba (83 km);

- Ao sul: Marzagão (34 km) e Corumbaíba (50 km);

-

- A leste: Ipameri $(60 \mathrm{~km})$;

- A oeste: Rio Quente (20 km), Morrinhos (54 km) e Piracanjuba $(83 \mathrm{~km})$.

No município, estão localizados quinze povoados, sendo os mais próximos: Nossa Senhora de Fátima, conhecida como Grupinho (12 km), Sapé (18 km), Junquerlândia (18 km), Tricolândia (35 km) e São Sebastião do Paraíso (40 km). 
Quadro 1

Distâncias das Principais Cidades

\begin{tabular}{|l|c|}
\hline \multicolumn{1}{|c|}{ Cidades } & Distância (Km) \\
\hline Goiânia & 162 \\
\hline Uberlândia & 198 \\
\hline Brasília & 290 \\
\hline Uberaba & 351 \\
\hline S. José do Rio Preto & 471 \\
\hline Araxá & 613 \\
\hline Belo Horizonte & 667 \\
\hline São Paulo & 781 \\
\hline Rio de Janeiro & 1.034 \\
\hline
\end{tabular}

Fonte: SETUR/Caldas Novas (GO).

\subsection{População e Densidade}

De acordo com dados do CENSO realizado em 2000 pelo Instituto Brasileiro de Geografia e Estatística (IBGE), Caldas Novas apresenta uma população fixa de 49.642 habitantes e, aproximadamente, 30 mil unidades residenciais construídas, com uma média por unidade domiciliar de 3,53 habitantes. Das residências, 65\% foram edificadas nos últimos 21 anos. Existem 60 mil lotes em disponibilidade. A população de Caldas Novas aumentou em $438 \%$ nos últimos 21 anos.

Tabela 1

Evolução da População

Período de 1842 - 2001

\begin{tabular}{|c|c|}
\hline Ano & Habitantes \\
\hline 1842 & 200 \\
\hline 1960 & 5.200 \\
\hline 1970 & 7.000 \\
\hline 1980 & 9.800 \\
\hline 1991 & 25.000 \\
\hline 2000 & 49.642 \\
\hline 2001 & 52.771 \\
\hline
\end{tabular}

Fonte: IBGE e Prefeitura Municipal de Caldas Novas (GO). 


\subsection{Serviços Básicos e Essenciais ${ }^{1}$}

O sistema de abastecimento de água de Caldas Novas é gerenciado pelo Departamento Municipal de Água e Esgoto (DEMAE). O manancial de captação é o Ribeirão Pirapetinga, localizado a $7 \mathrm{~km}$ da área urbana ocupada, com um volume diário de água armazenada de $10 \mathrm{mil} \mathrm{m}^{3}$.

Com uma rede de distribuição de 190 mil metros de extensão, o sistema abastece 15.067 residências, com medição de consumo através de hidrômetros na maioria das residências e estabelecimentos comerciais.

A varrição e a limpeza são feitas diariamente em 120km dos 190km pavimentados (asfalto e paralelepípedos). No período das chuvas, realiza-se a desobstrução de galerias de águas pluviais e das "bocas-de-lobo".

O abastecimento de energia elétrica da cidade é de responsabilidade das Centrais Elétricas de Goiás (CELG). De origem de hidroelétrica, o sistema é interligado aos de Cachoeira Dourada e de Emborcação, ambos na divisa dos Estados de Goiás e Minas Gerais.

A potência energética é de $40.700 \mathrm{KW}$, tensão de transmissão de $69 \mathrm{KV}$, capacidade da unidade transformadora de 40MVA, voltagem de distribuição residencial de $220 \mathrm{~V}$ e industrial de $220-380 \mathrm{~V}$.

O sistema de telefonia é atendido pela Brasil TELECOM (fixo), GVT (fixo), Telegoiás Celular - VIVO (móvel), CLARO (móvel) e TIM (móvel). Não foi possível obter dados sobre o sistema telefônico de Caldas Novas, uma vez que as solicitações não foram atendidas, sob alegação de serem confidenciais. A Agência Nacional de Telecomunicação (ANATEL), também consultada, não divulga esses dados.

\footnotetext{
${ }^{1}$ Fonte: Plano de Diretor de Caldas Novas (GO).
} 
Empiricamente, deduz-se que a telefonia celular supre a demanda dos turistas por uma maior comunicação telefônica.

A cidade possui cinco hospitais: três particulares (Hospital Geral, Hospital Nossa Senhora Aparecida e Hospital Santa Mônica) e os convênios mais utilizados são SUS e UNIMED; e dois públicos (Pronto Socorro Municipal e Hospital Materno Infantil).

\section{Quadro 2}

Rede Hospitalar

\begin{tabular}{|l|c|c|c|}
\hline \multicolumn{1}{|c|}{ Hospitais } & Leitos & Médicos & $\begin{array}{c}\text { Número de } \\
\text { Convênios }\end{array}$ \\
\hline Geral & 38 & 10 & 40 \\
\hline Nossa Senhora Aparecida & 37 & 25 & 23 \\
\hline Santa Mônica & 18 & 09 & 10 \\
\hline $\begin{array}{l}\text { Pronto Socorro Municipal e } \\
\text { Materno Infantil }\end{array}$ & 62 & 40 & 1 \\
\hline
\end{tabular}

Fonte: Autor

As instituições de ensino superior são: Faculdade de Caldas Novas (UNICALDAS), que oferece os cursos de Administração, Ciências Contábeis, Pedagogia, Secretariado Executivo, Sistema de Informação, Turismo, Master in Business Administration (MBA) - Gestão Empresarial e Psicopedagógico, perfazendo um total 1.100 alunos matriculados, somente no período noturno; Universidade Estadual de Goiás - (UEG), que oferece os cursos de Administração com habilitação em Hotelaria, Pedagogia, Letras e, de forma modular, o curso de Ciências Imobiliárias, com o total de 800 alunos matriculados no período noturno. Também oferece, por extensão, o "Projeto Vaga-lume", que é um curso de alfabetização para 400 jovens e adultos matriculados, ministrado por professores voluntários de Pedagogia.

A Rede Escolar de Caldas Novas, da alfabetização ao ensino médio, conta atualmente com 8 escolas estaduais, 26 municipais e 20 particulares, com a distribuição do número de alunos indicada no (Quadro 3). 
Quadro 3

Rede Escolar

\begin{tabular}{|c|c|c|c|c|}
\hline \multicolumn{2}{|c|}{ Escolas } & \multicolumn{3}{c|}{ Alunos } \\
\hline N. $^{\circ}$ & Instituição & Alfabetização & Fundamental & Médio \\
\hline 08 & Estadual & - & 5.678 & 2.611 \\
\hline 26 & Municipal & 37 & 4.700 & - \\
\hline 20 & Particular & 218 & 1.304 & 307 \\
\hline \multicolumn{2}{|l|}{ TOTAL } & & $\mathbf{1 4 . 8 5 5}$ \\
\hline
\end{tabular}

Fonte: Secretaria Regional de Educação, com sede em Morrinhos (GO).

\subsection{Economia da Cidade}

A principal atividade econômica do município é o turismo, seguidas por pecuária, agricultura e extrativismo mineral ${ }^{2}$. Essas atividades são baseadas nas características ambientais do município, onde o solo e a vegetação favorecem à agropecuária e as águas termais impulsionam a indústria do turismo.

Os produtos e serviços turísticos - resultantes da combinação dos atrativos naturais e culturais, equipamentos e serviços e infra-estrutura de apoio que trabalhados conjuntamente passam a possuir valor no mercado - têm características bastante peculiares, como a imobilidade, ou seja, o turista consumidor é que procura pelo produto. Em outras palavras, é o cliente que se desloca para a área de consumo. O momento da produção coincide com o da distribuição e, muitas vezes, com o de consumo também. Esses aspectos dificultam a atuação das empresas de forma isolada.

Atualmente, as modalidades de turismo mais praticadas podem ser entendidas a partir da seguinte classificação: turismo de eventos e negócios. ANSARAH (2000, pág. 75e 77) destaca que:

O turismo de eventos é a parte do turismo que leva em consideração o critério relacionado ao objetivo da atividade turística. É praticado com interesse profissional e cultural através de congressos, convenções, simpósios, feiras, encontros culturais, reuniões internacionais, entre outros, e é uma das atividades econômicas que mais crescem no mundo. (...)

\footnotetext{
${ }^{2}$ Fonte: Plano de Diretor de Caldas Novas (GO).
} 
Os eventos são um potencial multiplicador turístico, pois normalmente implicam no desenvolvimento de duas pessoas (o congressista e o acompanhante), ajudam a reduzir sensivelmente a sazonalidade, criam uma imagem positiva da cidade sede, mobilizando o "trade" turístico e, por conseqüência, os prestadores de serviços, gerando emprego e renda de imediato e proporcionando o ingresso de divisas para o país, estado ou cidade.

Segundo DUMAZEDIER (1980, p. 18), lazer é:

Um conjunto de ocupações as quais o individuo pode entregar-se de livre vontade, seja para repousar, seja para divertir-se, recrear-se e entreter-se, ou ainda para desenvolver sua informação ou formação desinteressada, sua participação social voluntária ou sua livre capacidade criadora após livrar-se ou desembaraçar-se das obrigações profissionais, familiares e sociais.

O turismo de lazer é o mais procurado, entretanto, fadado a esgotar-se muito em breve, caso não haja uma interseção com outras formas praticadas notório, já neste século, o esgotamento do turismo de balneário, caracterizado pela corrida exacerbada aos destinos de "sol e mar", uma vez que o homem adquiriu outras necessidades socioculturais e ambientais. Já o turismo de eventos e de negócios tem crescido muito por causa das necessidades impostas pelo capitalismo globalizado.

O mercado nacional de hotelaria e turismo é responsável por 3,5\% do Produto Interno Bruto (PIB), com um faturamento anual de R\$ 53 bilhões e potencial para $\mathrm{R} \$ 221$ bilhões nos próximos dez anos. De acordo com a EMBRATUR, só nos próximos três anos, desembarcarão no país investimentos da ordem de US\$ 6 bilhões. Existe, atualmente, 300 hotéis em construção no País, que irão gerar cerca de 600 mil empregos diretos e indiretos. Grande parte destes números demonstram que a hotelaria nacional está recebendo grande investida por parte das redes internacionais.

Até 2005 , a Atlantica Hotels International ${ }^{3}$ prevê o lançamento de mais de 20 empreendimentos em todo o País. Inicialmente segmentando a categoria econômica a superior em novos pólos de turismo de negócios e lazer. Entre os lançamentos, têm-se as cidades de Rio Verde e de Caldas Novas (GO).

\footnotetext{
${ }^{3}$ Fonte: Atlatica Hotels anucia mais de 20 abertura até 2005, Mercado 23 de outubro de 2003 www.hotelnews.com.br
} 
A Rede Espanhola Meliá ${ }^{4}$ criou o segmento econômico Sol Inn Brasil e, também, prevê lançamento para março de 2005 de duas unidades em Goiás: Goiânia e Anápolis.

\subsection{Turismo}

De acordo com a OMT (1994)

O Turismo compreende as atividades que as pessoas realizam durante suas viagens e estadias a lugares diferentes do seu local de residência, por um período consecutivo e inferior a um ano, com propósitos de lazer, descanso, negócios e outros.

\section{Quadro 4}

SEGUNDO A OMT

\begin{tabular}{|cc|}
\hline Hotéis & Hospedarias e Pensões \\
médio e grande porte & pequeno porte \\
(+ de 20 UHs) & (De 5 a 20 UHs) \\
Organizados de forma de edifícios & Aspectos familiares, administrados \\
pelos próprios proprietários. \\
Recebe a maioria do fluxo internacional \\
(demanda) & $\begin{array}{c}\text { Responsável pela maior parte da oferta } \\
\text { de leitos no mundo. }\end{array}$ \\
$20 \%$ da oferta de leitos no mundo & $80 \%$ da oferta de leitos no mundo \\
$80 \%$ do fluxo internacional & $20 \%$ do fluxo internacional. \\
\hline
\end{tabular}

Fonte: Apostila - GH, III, CET/UnB, Módulo 6, 2003. Pág. 5.

Um levantamento realizado pela SETUR em 2003 comprova que, há dez anos, Caldas Novas recebia Cinco mil turistas por ano e que em 2003, já são 150 mil visitantes por mês.

Foi inaugurado, em outubro de 2003 o funcionamento do Terminal de Embarque do Aeroporto Internacional de Caldas Novas e a SETUR espera

\footnotetext{
${ }^{4}$ Fonte: Mercado 23 de outubro de 2003 - www.hotelnews.com.br
} 
crescimento aproximado de $40 \%$ devido aos 40 vôos fretados por mês, 12 por semana, originários de Brasília, Goiânia, São Paulo e Rio de Janeiro.

A rede hoteleira cresceu $15,6 \%$ nos últimos cinco anos ${ }^{5}$, tornando-se a principal atividade econômica, a maior fonte de emprego e a segunda em UHs da região Centro-Oeste.

Em entrevista ao jornal Diário da Manhã, de 5 de março de 2002, Sérgio Palmerston, empresário do ramo hoteleiro, declarou que a taxa média de ocupação do município é de 45\%. Na atualidade, os meios de hospedagem, como: hotéis, clube-hotéis, pousadas, apart-hotéis, flats e pensões perfazem aproximadamente 100 empresas. Com isso, sua infra-estrutura oferece 3.555 UHs, 12.783 leitos e 170 piscinas. Até o final de $2003^{6}$, com os novos flats a oferta será de 23.052 leitos distribuídos em 5.447 apartamentos, que recebem cerca de 1,6 milhão de turistas anualmente.

Serão destacados, os meios de hospedagem com mais de 5 e até 20 UHs na cidade de Caldas Novas (GO):

\footnotetext{
${ }^{5}$ SETUR/Caldas Novas (GO).

${ }^{6}$ O Popular/ Goiasnet.com , 31 de março de 2003 : Caldas e Rio Quente querem mais turistas.
} 
Quadro 5

Meios de Hospedagem com mais de 5 e até 20 UHs.

\begin{tabular}{|c|l|c|c|}
\hline & \multicolumn{1}{|c|}{ Meios de Hospedagem } & UHs & Leitos \\
\hline 1 & Casablanca Thermas Hotel & 20 & 72 \\
\hline 2 & Hospedaria Regina & 10 & 30 \\
\hline 3 & Hotel Logus & 08 & 24 \\
\hline 4 & Hotel Orion & 13 & 39 \\
\hline 5 & Hotel Real & 19 & 60 \\
\hline 6 & Hotel Riviera & 15 & 61 \\
\hline 7 & Hotel Silva & 15 & 33 \\
\hline 8 & Hotel Stela & 07 & 21 \\
\hline 9 & Hotel e Restaurante Silva & 15 & 45 \\
\hline 10 & Hotel São José & 06 & 12 \\
\hline 11 & Hotel Serra Dourada & 20 & 49 \\
\hline 12 & JV Chalés & 05 & 25 \\
\hline 13 & Manhattan Hotel & 18 & 50 \\
\hline 14 & Minas Hotel & 10 & 20 \\
\hline 15 & Nossa Senhora Aparecida & 11 & 37 \\
\hline 16 & Pereiras's Chalés & 07 & 42 \\
\hline 17 & Pousada Arco Íris & 12 & 32 \\
\hline 18 & Pousada Cantinho Feliz & 12 & 45 \\
\hline 19 & Pousada Cristo Rei & 14 & 50 \\
\hline 20 & Pousada do Alan & 16 & 30 \\
\hline 21 & Pousada do Chá & 14 & 51 \\
\hline 22 & Pousada do Japão & 11 & 44 \\
\hline 23 & Pousada Dona Evanilda & 10 & 32 \\
\hline 24 & Pousada Nacional & 12 & 35 \\
\hline 25 & Recanto da Amizade & 06 & 32 \\
\hline 26 & Suíte Tateno & 08 & 24 \\
\hline & Total & 314 & 995 \\
\hline
\end{tabular}

Fonte: SETUR/Caldas Novas (GO) 


\section{ACESSOS}

Sabe-se que o turista de hoje é bastante exigente por obter mais informações e por ser conhecedor de outros destinos turísticos. Na realidade, o turista atual é multiconsumidor, vive renovação constante, criando novas necessidades como meio de encontrar a qualidade.

Ele pode apresentar três origens: internacional, nacional e regional. O turista internacional tem maior permanência, alto poder aquisitivo, é exigente em qualidade e infra-estrutura e geralmente pratica o turismo de negócios. O nacional também utiliza transporte aéreo, tem permanência média/curta e nível médio de exigência. O regional geralmente utiliza transporte rodoviário, é menos exigente e tem menor poder aquisitivo.

A seguir, estão relacionadas as principais rodovias e cidades que se ligam ao Município de Caldas Novas através dessas vias, com duas delas interligadas com rodovias federais.

\section{Quadro 6}

Acessos Rodoviários e Cidades

\begin{tabular}{|c|c|c|}
\hline Direção & Rodovias & Cidade(s) \\
\hline Norte & GO-413 & Piracanjuba \\
\hline Leste & $\begin{array}{c}\text { GO-213 } \\
\text { GO-210/319 }\end{array}$ & Pires do Rio / Ipameri \\
& GO-213 & Morrinhõo \\
\hline Oeste & $\begin{array}{c}\text { Rodovias } \\
\text { Interligadas }\end{array}$ & Cidade (s) \\
\hline Direção & BR-050/MG-139 & São Paulo / Araguari \\
& MG-139/GO-217 & Araguari / Marzagão a Caldas Novas \\
\hline Sul & BR-153 & São Paulo/Goiânia \\
& GO-213 & Goiânia / Morrinhos/Caldas Novas \\
\hline Oeste & &
\end{tabular}

Fonte: SETUR/Caldas Novas (GO) 


\subsection{Transporte Rodoviário}

A empresa Paraúna é a única que faz o transporte urbano de passageiros, oferece quatro linhas definidas pelos nomes de Country, das Mansões, do Bouganville e do Chocolate. Existem também linhas intermunicipais de transporte coletivo que ligam Caldas Novas a Rio Quente e Morrinhos.

A partir de Caldas Novas, sete empresas fazem o transporte regional e nacional.

\section{Quadro 7}

Empresas de Transporte Rodoviário

\begin{tabular}{|c|c|}
\hline \multicolumn{2}{|c|}{ Viação Estrela } \\
\hline Destino & Partidas \\
\hline Goiânia (direto) & $6 h-16 h-18 h$ \\
\hline Brasília (embarque em Morrinhos) & $23 \mathrm{~h}$ \\
\hline \multicolumn{2}{|c|}{ Viação Transcol } \\
\hline Destino & Partidas \\
\hline Morrinhos, Itumbiara e Uberlândia. & $7 \mathrm{~h}$ e $17 \mathrm{~h}$ \\
\hline \multicolumn{2}{|c|}{ Expresso Araguari } \\
\hline Destino & Partidas \\
\hline Uberlândia & $7 h-12 h 30-15 h 30-19 h$ \\
\hline Vianópolis e Anápolis (quarta e quinta-feira) & $6 \mathrm{~h}$ \\
\hline \multicolumn{2}{|c|}{ Viação Alfa Luz } \\
\hline Destino & Partidas \\
\hline Caldas Novas - Brasília & $\begin{array}{r}6 h 30-8 h-14 h \text { (direto) } \\
14 h 05 \text { (via Ipameri) } \\
16 h 30 \text { (direto aos domingos) } \\
\end{array}$ \\
\hline \multicolumn{2}{|c|}{ Viação Paraúna } \\
\hline Destino & Partidas \\
\hline Anápolis & $18 \mathrm{~h}$ \\
\hline Catalão & $16 h$ \\
\hline Goiânia & $\begin{array}{r}6 h 30-7 h 30-9 h-11 h 50-13 h \\
15: 00-17 h-17 h 45-19 h 30 \\
\end{array}$ \\
\hline Pousada e Morrinhos & $\begin{array}{r}6 h 15-7 h-8 h-9 h \\
10 h-11 h 30-12 h 30-14 h \\
15 h 45-17 h-18 h-20 h 30\end{array}$ \\
\hline Rio Quente & $9 h$ e $19 h$ \\
\hline
\end{tabular}


Quadro 7

Empresas de Transporte Rodoviário

continuação

\begin{tabular}{|c|c|}
\hline \multicolumn{2}{|c|}{ Expresso União } \\
\hline Destino & Partidas \\
\hline Rio de Janeiro & $10 h 30$ e $15 h$ \\
\hline Belo Horizonte & $10 h 30$ e $19 h 30$ \\
\hline Aparecida do Norte & $15 \mathrm{~h}$ \\
\hline Pirassununga & $15 \mathrm{~h}$ \\
\hline Palmas & $10 h 30$ \\
\hline São José dos Campos & $15 \mathrm{~h}$ \\
\hline \multicolumn{2}{|c|}{ Nacional Expresso e Ludetur Turismo } \\
\hline Destino & Partidas \\
\hline Barra do Garça & 2h15 \\
\hline Campinas & $20 h 45$ \\
\hline Curitiba & $13 \mathrm{~h}$ \\
\hline Piracicaba & $20 \mathrm{~h}$ \\
\hline Ribeirão Preto & $10 h 30$ e $19 h 15$ \\
\hline São José dos Campos & 19h15 \\
\hline São José Rio Preto & $17 \mathrm{~h}$ \\
\hline São Paulo & 10h30-19h15-16h30-17h e 20h \\
\hline Uberaba & $10 h 30$ e $16 h 30$ \\
\hline Uberlândia & 17h -19h15 - 16h30 e 20h \\
\hline Santos & 10h30 \\
\hline
\end{tabular}

Fonte: SETUR/Caldas Novas (GO) 


\section{ABORDAGEM METODOLÓGICA}

\subsection{Delimitação do Universo da Pesquisa}

Os hotéis podem ser classificados de diversas formas: pelo tamanho, pelo tipo de serviços que oferece, pelo tipo de $\mathrm{UH}$, pelo número de leitos, pela receita anual ou, até mesmo, pela auto classificação. Segundo CASTELLI (1997, pág. 26), as empresas hoteleiras podem ser classificadas, quanto ao seu tamanho, em pequenas, médias e grandes.

O presente estudo concentra-se nos hotéis (de auto classificação) que tenham mais de 5 e até 20 UHs e incluso café-da-manhã na diária, ou seja, hotéis de pequeno porte (categoria econômica), administrados pelo próprio proprietário, cuja diária média é de $\mathrm{R} \$ 35,00$ o casal.

\subsection{Universo da Pesquisa}

Os dados primários foram realizados pelo autor nos 26 hotéis de pequeno porte (categoria econômica), administrado pelo próprio proprietário e que tenham mais de 5 e até 20 UHs e, os dados secundários, pela AGETUR, em dois períodos: o primeiro, na baixa temporada, em maio de 2002; e o segundo, na alta temporada, em julho de 2002, ambos.em Caldas Novas (GO).

\subsection{Sazonalidade}

Os meios de hospedagem convivem com a sazonalidade que afeta diretamente o turismo. Isso ocorre em função de diversos fatores, dentre ele os ciclos de atividades econômicas, as variações do clima, as férias escolares, as temporadas de festas e os feriados.

A sazonalidade do turismo em Caldas Novas é demonstrada por meio de pesquisa realizada pela AGETUR, em 2002. 
De acordo com Sérgio Palmerston, empresário do ramo hoteleiro, declarou em entrevista ao jornal Diário da Manhã, de 5 de maio de 2002, a taxa média de ocupação do município é de $45 \%$. 


\section{PÉRFIL DO TURISTA}

Quadro 8

Origem

\begin{tabular}{|l|c|c|}
\hline Origem & Baixa (Maio de 2002) & Alta (Julho de 2002) \\
\hline Distrito Federal & $18,54 \%$ & $21,25 \%$ \\
\hline Goiânia e Interior & $44,37 \%$ & $34,64 \%$ \\
\hline São Paulo & $16,67 \%$ & $18,04 \%$ \\
\hline Minas Gerais & $11,97 \%$ & $15,18 \%$ \\
\hline Outros estados & $8,45 \%$ & $10,89 \%$ \\
\hline
\end{tabular}

Fonte: AGETUR/Núcleo de pesquisa.

Os dados revelam que tanto na baixa quanto na alta temporada, existe um equilíbrio relacionado à origem dos turistas do Distrito Federal, São Paulo, Minas Gerais e outros estados. Mas houve uma redução de turistas de Goiânia e do interior de Goiás na alta temporada, que corresponde a uma queda de aproximadamente $10 \%$.

\section{Quadro 9}

Sexo

\begin{tabular}{|l|c|c|}
\hline Sexo & Baixa (Maio de 2002) & Alta (Julho de 2002) \\
\hline Feminino & $51,41 \%$ & $50,72 \%$ \\
\hline Masculino & $48,59 \%$ & $49,29 \%$ \\
\hline
\end{tabular}

Fonte: AGETUR/Núcleo de pesquisa.

\section{Quadro 10}

Idade

\begin{tabular}{|l|c|c|}
\hline Faixa Etária & Baixa (Maio de 2002) & Alta (Julho de 2002) \\
\hline 16 a 21 anos & $8,69 \%$ & $15,18 \%$ \\
\hline 22 a 40 anos & $47,42 \%$ & $46,61 \%$ \\
\hline 41 a 60 anos & $27,23 \%$ & $27,14 \%$ \\
\hline Acima de 61 anos & $8,92 \%$ & $8,04 \%$ \\
\hline Obs.: Em 7,75\% dos questionários houve incoerência nas respostas. \\
\hline
\end{tabular}

Fonte: AGETUR/Núcleo de pesquisa. 
Quadro 11

Estado civil

\begin{tabular}{|l|c|c|}
\hline Estado Civil & Baixa (Maio de 2002) & Alta (Julho de 2002) \\
\hline Solteiro & $33.57 \%$ & $38.57 \%$ \\
\hline Casado & $51.64 \%$ & $46.79 \%$ \\
\hline Desquitado/divorciado & $7.04 \%$ & $7.50 \%$ \\
\hline Viúvo & $7.28 \%$ & $5.89 \%$ \\
\hline Não respondeu & $0.47 \%$ & $1.25 \%$ \\
\hline
\end{tabular}

Fonte: AGETUR/Núcleo de pesquisa.

A maior presença foi constituída por indivíduos do sexo feminino 51,41\% na baixa e 50,72\% na alta. Já na faixa etária, prevalecem, em sua maioria os turistas com idade entre 22 e 40 anos. Com isso, pode-se verificar que existiu alta de turistas solteiros na alta temporada de $33.57 \%$ para $38.57 \%$ e queda dos casados de $51,64 \%$ para $46,79 \%$.

Quadro 12

Local de Hospedagem

\begin{tabular}{|l|c|c|}
\hline Local & Baixa (Maio de 2002) & Alta (Julho de 2002) \\
\hline HOTEL/POUSADA & $67.61 \%$ & $51.25 \%$ \\
\hline Com amigos/parentes & $10.80 \%$ & $16.61 \%$ \\
\hline Casa de veraneio própria & $10.80 \%$ & $12.86 \%$ \\
\hline Casa alugada & $8.92 \%$ & $10.71 \%$ \\
\hline Camping & $1.17 \%$ & $2.14 \%$ \\
\hline $\begin{array}{l}\text { Não estavam hospedados na } \\
\text { cidade }\end{array}$ & $0.70 \%$ & $6.43 \%$ \\
\hline
\end{tabular}

Fonte: AGETUR/Núcleo de pesquisa. 
Os dados revelam que a maior parcela $(67,61 \%)$ hospedou-se em hotel ou pousada na baixa temporada e queda na alta temporada para $51,25 \%$, mas, em contra partida, nesse mesmo período, houve alta em casa de amigos/parentes de $10,80 \%$ para $16,61 \%$.

Predominantemente, os maiores fluxos de turistas são provenientes do Distrito Federal, Goiânia e interior por sua proximidade a Goiás. No caso do Distrito Federal, houve redução de gastos de quase $50 \%$ na alta temporada (de $\mathrm{R} \$ 81,58$ para $\mathrm{R} \$ 43,87$ ), pois os consumidores procuravam outros tipos de acomodação, como: casa de amigos/parentes ou, até mesmo, os meios de hospedagem de categoria econômica (pequeno porte). Enquanto os turistas de Goiânia e do interior procuraram outros destinos na alta temporada com queda de quase $10 \%$.

\section{Quadro 13}

Gasto Médio

\begin{tabular}{|l|c|c|}
\hline Origem & Baixa (Maio de 2002) & Alta (Julho de 2002) \\
\hline Distrito Federal & $\mathrm{R} \$ 81.58$ & $\mathrm{R} \$ 43.87$ \\
\hline São Paulo & $\mathrm{R} \$ 54.01$ & $\mathrm{R} \$ 72.48$ \\
\hline Minas Gerais & $\mathrm{R} \$ 44.00$ & $\mathrm{R} \$ 58.24$ \\
\hline Goiânia e interior & $\mathrm{R} \$ 49.05$ & $\mathrm{R} \$ 42.98$ \\
\hline \multicolumn{1}{|c|}{ Outros estados } & $\mathrm{R} \$ 61.39$ & $\mathrm{R} \$ 119.60$ \\
\hline
\end{tabular}

Fonte: AGETUR/Núcleo de pesquisa.

Os turistas provenientes do Distrito Federal tiveram um gasto médio de R\$ 81,58 na baixa temporada e queda de gastos na alta. Os turistas de outros estados tiveram aumento de gasto na alta temporada de quase $51 \%$, ou seja, de $\mathrm{R} \$ 61,39$ (baixa) para $\mathrm{R} \$ 119,60$ (alta). Isso provocou reflexo nos meios de hospedagem, queda na ocupação, mas aumento de receita. 
Quadro 14

Renda Pessoal

\begin{tabular}{|l|c|c|}
\hline \multicolumn{1}{|c|}{ Renda } & Baixa (Maio de 2002) & Alta (Julho de 2002) \\
\hline Até um salário mínimo & $1.64 \%$ & $2.32 \%$ \\
\hline Entre R\$ 200 e R\$ 500,00 & $14.32 \%$ & $11.25 \%$ \\
\hline Entre R\$ 500,00 e R\$ 1.000,00 & $23,00 \%$ & $22.86 \%$ \\
\hline Entre R\$ 1.000,00 e R\$ 2.000,00 & $26.76 \%$ & $18.04 \%$ \\
\hline Entre R\$ 2.000,00 e R\$ 4.000,00 & $22,30 \%$ & $22.86 \%$ \\
\hline Acima de R\$ 4.000,00 & $8.69 \%$ & $14.29 \%$ \\
\hline Não Responderam & $3.29 \%$ & $18.39 \%$ \\
\hline
\end{tabular}

Fonte: AGETUR/Núcleo de pesquisa.

Na baixa temporada, evidenciou-se que 26,76\% dos turistas tinham renda pessoal entre $\mathrm{R} \$ 1.000,00$ e $\mathrm{R} \$ 2.000,00$, e, na alta temporada, houve alteração de valores na renda pessoal que foi de $R \$ 2.000,00$ e $R \$$ 4.000,00, correspondendo a $22,86 \%$ dos entrevistados. Foi considerável o aumento de aproximadamente $60 \%$ dos turistas com renda superior a $\mathrm{R} \$ 4.000,00$, passando de $8,69 \%$ para $14,29 \%$ na alta temporada. 
Quadro 15

Agrupamento

\begin{tabular}{|c|c|c|}
\hline Agrupamento & Baixa (Maio de 2002) & Alta (Julho de 2002) \\
\hline Um Casal & $21.36 \%$ & $9.11 \%$ \\
\hline Casal com Filhos & $11.03 \%$ & $16.25 \%$ \\
\hline Família & $14.32 \%$ & $29.64 \%$ \\
\hline Excursão & $16.43 \%$ & $10.18 \%$ \\
\hline Família e Amigos & $9.15 \%$ & $7.32 \%$ \\
\hline Grupos de amigos & $17.84 \%$ & $15.18 \%$ \\
\hline Sozinho & $8.92 \%$ & $9.46 \%$ \\
\hline Outros & $0.23 \%$ & $2.32 \%$ \\
\hline Não responderam & $0.23 \%$ & $0.54 \%$ \\
\hline
\end{tabular}

Fonte: AGETUR/Núcleo de pesquisa.

Pela peculiaridade das águas termais, é notória uma demanda superior de casais na baixa temporada devido: à baixa ocupação, aos preços mais favoráveis e à tranqüilidade. Da mesma forma, ficou evidente o aumento de excursões na baixa temporada, pois os hotéis reduzem seus preços para receberem excursões de escolas e grupos, como o de melhor idade (adultos acima de 60 anos).

Devido às férias escolares, aumenta-se a procura de famílias e casal com filhos na alta temporada, passando de 14,32\% para 29,64\%. Com isso, as empresas podem aumentar sua taxa de ocupação e receita, diminuindo a taxa de lucro para superar a alta sazonalidade. 
Quadro 16

Motivo da viagem

\begin{tabular}{|c|c|c|}
\hline Motivo & Baixa (Maio de 2002) & Alta (Julho de 2002) \\
\hline De passagem & $0.94 \%$ & $1.57 \%$ \\
\hline Negócios & $2.59 \%$ & $1.61 \%$ \\
\hline Turismo no município & $88.26 \%$ & $89.11 \%$ \\
\hline Visitando amigos/família & $6.34 \%$ & $7.71 \%$ \\
\hline Estudo/pesquisa & $0.70 \%$ & $0 \%$ \\
\hline Não respondeu & $1.17 \%$ & $0 \%$ \\
\hline
\end{tabular}

Fonte: AGETUR/Núcleo de pesquisa.

A turismo de lazer é bem evidente quando se refere à cidade de Caldas Novas como destino turístico, mas, quase que não existe o segmento de turismo de negócios, que aumentaria a taxa de ocupação dos meios de hospedagem, emprego (mão-de-obra), receita e tributos.

\section{Quadro 17}

Visita à região

\begin{tabular}{|l|c|c|}
\hline Quantidade de visitas & Baixa (Maio de 2002) & Alta (Julho de 2002) \\
\hline Primeira visita & $17.14 \%$ & $22.86 \%$ \\
\hline Já visitou antes & $81.94 \%$ & $76.25 \%$ \\
\hline Não responderam & $0.94 \%$ & $0.89 \%$ \\
\hline
\end{tabular}

Fonte: AGETUR/Núcleo de pesquisa.

Em sua maioria, os turistas que visitam a cidade, pela primeira vez, retornam na baixa temporada. Dos entrevistados, 81,94 \% voltam na baixa e 76,25 na alta. 
Quadro 18

Época de visitação

\begin{tabular}{|l|c|c|}
\hline Época & Baixa (Maio de 2002) & Alta (Julho de 2002) \\
\hline Dias úteis & $12.15 \%$ & $5.00 \%$ \\
\hline Feriados & $27.75 \%$ & $13.75 \%$ \\
\hline Férias & $8.86 \%$ & $68.57 \%$ \\
\hline Finais de semana & $51.24 \%$ & $16.96 \%$ \\
\hline
\end{tabular}

Fonte: AGETUR/Núcleo de pesquisa.

Ao contrário de várias cidades turísticas, é justamente nos finais de semana (sexta-feira a domingo) e feriados que os turistas aumentam a procura por Caldas Novas (GO).

Os dias úteis (segunda-feira a quinta-feira) de baixa temporada são os mais procurados devido aos representantes comerciais que se hospedam em hotéis de pequeno porte (categoria econômica), pois são estes que abastecem o comércio local: farmácias, drogarias, hospitais, hotéis, padarias, mercearias, supermercados, construção civil, dentre outros.

\section{Quadro 19}

Tempo de Permanência

\begin{tabular}{|l|c|c|}
\hline Dias & Baixa (Maio de 2002) & Alta (Julho de 2002) \\
\hline Mais de 7 dias & $3.05 \%$ & $10.00 \%$ \\
\hline De 4 a 7 dias & $27.93 \%$ & $48.57 \%$ \\
\hline De 1 a 3 dias & $56.10 \%$ & $23.21 \%$ \\
\hline Não responderam & $12.91 \%$ & $18.22 \%$ \\
\hline
\end{tabular}

Fonte: AGETUR/Núcleo de pesquisa.

O maior fluxo de turistas na baixa temporada, que permanece de 1 a 3 dias, corresponde a $56,10 \%$, justamente os feriados e finais de semana. Já na alta temporada prevalece a permanência superior a 4 dias que corresponde a $58,57 \%$. 
Quadro 20

Meios de Comunicação

\begin{tabular}{|l|c|c|}
\hline Meios de Comunicação & Baixa (Maio de 2002) & Alta (Julho de 2002) \\
\hline Agência & $0.70 \%$ & $9.29 \%$ \\
\hline Folhetos & $14.79 \%$ & $2.68 \%$ \\
\hline Jornal & $1.14 \%$ & $1.43 \%$ \\
\hline Livros & $11.97 \%$ & $0.54 \%$ \\
\hline Parentes e/ou amigos & $0.47 \%$ & $61.96 \%$ \\
\hline Placas e outdoors & $1.41 \%$ & $0.89 \%$ \\
\hline Rádio & $1.17 \%$ & $1.61 \%$ \\
\hline Revista & $0.23 \%$ & $2.68 \%$ \\
\hline Televisão & $6.57 \%$ & $16.79 \%$ \\
\hline Vídeo & $0.23 \%$ & $1.25 \%$ \\
\hline Outras pessoas & $65.25 \%$ & $5.00 \%$ \\
\hline
\end{tabular}

Fonte: AGETUR/Núcleo de pesquisa.

Fica evidente que as ferramentas do marketing são pouco utilizadas, predominando o "boca-a-boca", ou seja, indicações de parente e amigos.

O processo de comunicação é complexo, podendo ser subdividido nas áreas de propaganda, relações com a imprensa, relações públicas e promoções com clientes, feiras e eventos específicos do mercado de turismo.

Os empresários de trade turístico de Caldas Novas, sabedores desses dados, devem formar uma estratégia para manter os turistas freqüentes e captar outros. Ou seja, os hóspedes dos hotéis devem ser induzidos à repetição e à recomendação, deve-se divulgar a qualidade dos serviços, informar sobre novos produtos e promoções.

Pois o consumidor buscará mais informações sobre o produto que deseja adquirir, lerá brochuras, consultará amigos e páginas da internet, procurará um agente de viagens e, possivelmente, assistirá até a um vídeo. A quantidade de 
aspectos a examinar e a ponderar serão maiores antes de optar por este ou aquele produto.

No caso dos hotéis de pequeno porte (categoria econômica), o consumidor buscará informações básicas, com as quais tomará decisão rápida. Nesse sentido, listas telefônicas, os guias disponíveis na internet ou em brochuras são suficientes e de grande utilidade, tanto para os consumidores (turistas), como os ofertantes (empresas).

\section{Quadro 21}

Meios de Transporte

\begin{tabular}{|l|c|c|}
\hline Meio de transporte & Baixa (Maio de 2002) & Alta (Julho de 2002) \\
\hline Avião & $1.66 \%$ & $1.25 \%$ \\
\hline Carro & $61.03 \%$ & $70.00 \%$ \\
\hline Moto & $0.70 \%$ & $1.43 \%$ \\
\hline Ônibus & $35.68 \%$ & $25.75 \%$ \\
\hline Outros & $0.23 \%$ & $0.36 \%$ \\
\hline Não responderam & $0.70 \%$ & $1.21 \%$ \\
\hline
\end{tabular}

Fonte: AGETUR/Núcleo de pesquisa.

Os dados revelam que a maioria dos turistas faz deslocamento de carro próprio, na baixa temporada com $61,03 \%$ e, na alta, $70 \%$. Os que vêem em excursões e grupos utilizam ônibus na baixa $35,68 \%$ e, na alta, a queda é para $25,75 \%$.

\section{Quadro 22}

Acesso aos guias

\begin{tabular}{|l|c|c|}
\hline Acesso aos guias & Baixa (Maio de 2002) & Alta (Julho de 2002) \\
\hline Sim & $25.82 \%$ & $13.57 \%$ \\
\hline Não & $74.18 \%$ & $85.18 \%$ \\
\hline Não Responderam & $0 \%$ & $1.25 \%$ \\
\hline
\end{tabular}

Fonte: AGETUR/Núcleo de pesquisa. 
Fica evidente a dificuldade de acesso aos guias, pois, não houve acompanhamento de guias tanto na baixa temporada quanto na alta. Ou seja, $74,18 \%$ por turistas entrevistados não encontraram os guias e, na alta, $85,15 \%$. 


\section{CONCLUSÃO}

Ressalta-se que, de modo geral, o desenvolvimento do segmento hoteleiro de Caldas Novas (GO) não escapa aos padrões observados nos principais destinos turísticos. A recente proliferação de flats, algumas vezes organizados em clubes, parece emergir no mercado.

Entretanto, resultados conclusivos só poderiam ser obtidos após estudo de todos os meios de hospedagem, a fim de avaliar, com precisão, o real significado do impacto dos flats nos hotéis de pequeno porte (categoria econômica). Embora o segmento hoteleiro do Município esteja em expansão moderada, percebe-se que a falta de políticas públicas adotadas por gestores municipais e estaduais vão ao encontro à realidade e à necessidade do trade turístico, ou seja, como resolver a sazonalidade? Uma vez que foram orçados recursos significativos para investimento em tratamento de esgoto, reforma e ampliação do Centro de Convenções, para realização de turismo de eventos e negócio e com a inauguração do Aeroporto Internacional, a cidade proporcionará aos turistas facilidades de deslocamento. Haverá, assim, aumento do fluxo de turistas, em virtude da expectativa de que as novas instalações tragam vôos regulares de grandes companhias aéreas, bem como a construção do Ginásio de Esportes com vistas a atrair e incentivar campeonatos municipais, estaduais, federais e até internacionais.

Indiscutivelmente, o chamado turismo de eventos e negócios vive um momento de grande expansão, podendo impulsionar a atividade turística nas temporadas de baixa estação. Essa modalidade cresce de forma assustadora devido ao processo de globalização nas empresas que precisam realizar convenções sistemáticas, reuniões, feiras, recompensa de vendedores, treinamentos, lançamentos de produtos e outros.

Portanto, esse segmento mostra-se como uma das principais alternativas de geração de emprego e renda no Brasil, além de apresentar vantagens em relação ao turismo de lazer, mundialmente consolidado, uma vez que o turista que 
viaja a trabalho gasta, em média, três vezes mais que aquele que procura apenas descansar. Vale destacar a importância de se evoluir para um modelo de desenvolvimento sustentável do turismo de lazer, geração de empregos, em que é fundamental a participação da comunidade no planejamento da atividade turística, sendo o princípio da oportunidade, da criatividade, da inovação e do empreendedorismo que são de vital importância para o desenvolvimento do Setor. 


\section{REFERÊNCIAS BIBLIOGRÁFICAS}

AGETUR. Turismo em dados - Caminho das Águas. Goiás - Brasil, Goiânia, 2002.

ANDRADE, J. V. de. Turismo: fundamentos e dimensões. 5. ed. São Paulo: Ática, 1998.

ANDRADE, N.;BRITO, P. L. de; JORGE, W. E. Hotel: planejamento e projeto.2. ed. São Paulo: SENAC, 2000.

ANSARAH, M. G. dos R. Turismo: segmentação de mercado. São Paulo: Futura, 2000.

BENI, M. C. Analise estrutural do turismo. 4. ed. São Paulo: Senac, 2001.

CASTELLI, G. Administração hoteleira. 7. ed. Caxias do Sul: EDUCS, 1997.

COLTMAN, M. M. Introduction to travel \& tourism: an international approach. New York: Van Nostrand Reinhold, 1989.

DIAS, C. M. M. Hospitalidade: Reflexões e perspectivas. São Paulo: Manole, 2002.

DUARTE, V. V. Administração de sistemas hoteleiros: conceitos básicos. São Paulo: SENAC, 1996.

DUMAZEDIER, J. Planejamento de lazer no Brasil: a teoria sociológica de decisão. São Paulo: SESC, 1980.

FLORENTINO, M.; PARENTE, J. Gestão e qualidade nos serviços de Hospitalidade. Apostila GH-III - Módulo:6 do Centro de Excelência em Turismo da Universidade de Brasília, maio, 2003. 
IGNARRA, L. R. Fundamentos do turismo. São Paulo: Pioneira, 1999.

IRVING, M. de A.; AZEVEDO, J. Turismo: o desafio da sustentabilidade. São Paulo: Futura, 2002.

LA TORRE, F. De. Administração hoteleira, Parte I: departamentos. São Paulo: ROCCA, 2001.

LIGUORI, S.; GRAY, W. S. Hotel and motel: management and operations. 2. ed. New Jersey: Prentice Hall, 1990.

Manual de Orientações para produção de textos acadêmicos. Disponível em <www.unb.br/cet> . Acesso em 25 de junho de 2003.

MEDLIK, S.; INGRAM, H. Introdução à hotelaria: gerenciamento e serviços. Rio de janeiro: Campus, 2002.

OLIVEIRA, Antonio Pereira. Turismo e desenvolvimento: planejamento e organização. 2. ed. Ver. E ampl. - São Paulo: Atlas, 2000.

PETROCCHI, M. Hotelaria: planejamento e gestão. São Paulo: Futura, 2002.

Plano diretor da Prefeitura de Caldas Novas (GO). Disponível em <www.caldasonline.com.br/planodiretort > . Acesso em 14 de janeiro de 2003.

VALLEN, G. K.; VALLEN, J. J. Check-in, check-out: gestão e prestação de serviços em hotelaria. 6. ed. Porto Alegre: Bookman, 2003. 